\title{
Dinamika Relasi Keluarga ODS (Orang dengan Skizofrenia) Usia Remaja Berdasarkan Teori Bowen
}

\author{
The Dynamic of Family Relationship in a Teenager with \\ Schizophrenia based on Bowen Theory
}

\author{
Hani Kumala ${ }^{1}$ Irwanto Irwanto ${ }^{2}$ \\ 1,2Fakultas Psikologi, Universitas Katolik Indonesia Atma Jaya
}

Submitted 19 November 2020 Accepted 3 February 2021 Published 28 May 2021

\begin{abstract}
Schizophrenia is one the most severe forms of mental illness. It is a long term chronic condition involving a serious disorder in perception of reality with frequent relapses. Only $10 \%$ PWS (Persons with Schizophrenia) can function well under medication-only treatment. The rest $(90 \%)$ need other treatments including family therapy. Family is considered as the most important in the etiology as well as the recovery of schizophrenia. This was a single case study of Bowen Family Therapy to a family with a schizophrenic youngest daughter. Data were collected using interviews to the father, mother, the Index Person (IP), and her older sister. The result of the study indicated that a failure to achieve self-differentiation was heavily influenced by the intensity of emotional relationship with other family members. Parents' (second generation) poor self-differentiation from their original families (first generation) caused the onset of schizophrenia in the youngest daughter (third generation) who was caught in a doublebind messages. Her schizophrenic syndrome seem to be her only way of coping with that situation.
\end{abstract}

Keywords: bowen family therapy; double bind messages; schizophrenia; teenager; differentiation

Abstrak. Skizofrenia adalah salah satu gangguan mental yang berat. Perjalanan penyakitnya kronis dan sering kambuh. Tidak lebih dari 10\% ODS berfungsi baik hanya dengan pengobatan anti psikotik. Sembilan puluh persen sisanya tetap membutuhkan pendekatan dinamis termasuk juga terapi keluarga. Pendekatan dinamis berarti diperlukan kerjasama berbagai pihak untuk membantu pemulihan. Keluarga merupakan faktor penting, baik dalam etiologi maupun pemulihan ODS. Penelitian ini merupakan intervensi single case study dengan Bowen Family Therapy terhadap keluarga yang mengalami skizofrenia. Data diperoleh melalui wawancara terhadap ayah, ibu, Index Person, dan kakak perempuannya. Hasil penelitian menggambarkan bahwa kemampuan melakukan diferensiasi sangat dipengaruhi oleh intensitas relasi emosi dari anggota keluarga lain. Diferensiasi diri yang dari buruk ayah dan ibu (generasi kedua), menyebabkan munculnya gangguan skizofrenia pada salah satu anak perempuannya (generasi ketiga) yang terjebak dalam double bind-messages.

Kata kunci: bowen; pesan ganda; remaja; skizofrenia; terapi keluarga

Skizofrenia merupakan salah satu gangguan mental yang berat (NIMH, 2016). Gejalanya adalah pemikiran tidak logis, persepsi keliru, afek datar dan gangguan aktivitas motorik 
yang tidak masuk akal (Davison et al., 2004). Prevalensi global untuk skizofrenia berkisar $1-1.3 \%$ dan ditemukan pada semua lapisan sosial, pendidikan, ekonomi, dan ras (Surilena, 2005). Tahun 2013, Guru Besar Ilmu Kesehatan Masyarakat Universitas Indonesia, Ascobat Gani menambahkan bahwa kerugian ekonomi akibat gangguan jiwa di Indonesia sebesar Rp 20 T (Taufik, 2013). Data WHO tahun 2015 menunjukkan bahwa Indonesia berada di peringkat pertama dari 192 negara dengan nilai DALY's (Disability Adjusted Life Year) skizofrenia tertinggi (Penentuan kapasitas, 2015). Berdasarkan Hasil Riset Kesehatan Dasar (Riskesdas) tahun 2018, penderita gangguan jiwa berat di Indonesia adalah 0,7\%. Data ini naik hampir 100\% dari tahun 2007 yang berada di angka $0,46 \%$.

Skizofrenia dikenal sebagai heterogeneous disorder, artinya gangguan yang ditandai dengan banyak manifestasi. Hingga saat ini, tidak ada penelitian yang menyatakan bahwa genetis adalah faktor tunggal penyebab skizofrenia (Pramudya, 2014; McGrath \& Murray, (dalam Weinberger \& Harrison, 2011); Krabbendam \& van Os, 2005). Para ahli klinis tetap menemukan adanya dinamika dari reaksi individual yang kompleks sebagai penyebab munculnya gangguan skizofrenia. Skizofrenia muncul lebih awal pada laki-laki yaitu usia 10-25 dan 25-35 tahun pada perempuan. Namun tidak menutup kemungkinan skizofrenia terjadi lebih awal atau akhir (Pramudya, 2014). Sekalipun tekonologi dalam dunia pengobatan ODS (Orang dengan Skizofrenia) terus berkembang hingga efek samping obat yang dirasakan semakin minim (Chandra, 2010), namun tidak lebih dari $10 \%$ ODS yang dapat berfungsi baik hanya dengan penggunaan obat anti psikotik saja. Sembilan puluh persen sisanya tetap membutuhkan berbagai pendekatan termasuk terapi keluarga (Pramudya, 2014; Krabbendam \& van Os, 2005). Ini berarti diperlukan kerjasama berbagai pihak untuk membantu pemulihan ODS. Tidak bisa jika satu pihak saja yang bertanggung jawab.

Bagus Utomo, pendiri KPSI (dalam Taufik, 2013) mengatakan bahwa perawatan ODS dimulai dari perawatan di rumah sakit, pemberian obat, sampai dengan dukungan sosial, keluarga dan masyarakat. Jadi diperlukan kerja sama multi faktor untuk proses pemulihan ODS. Dapat dikatakan bahwa keluarga merupakan aspek yang penting dan mungkin merupakan yang paling konsisten dalam kehidupan ODS. Hal ini disebabkan karena lebih dari $60 \%$ ODS yang keluar dari rumah sakit akan kembali pada keluarga. Keadaan ODS akan membaik jika keluarga terlibat pengobatan (Pramudya, 2014). Penelitian Ivanti (2001) mengungkapkan bahwa keluarga memiliki peran penting dalam mencegah kekambuhan pasien. Tomb (2004) menambahkan bahwa kekambuhan biasanya berhubungan signifikan dengan emosi yang berlebihan terutama dalam keluarga. Selain itu, terapis keluarga percaya bahwa sumber kekuatan hidup utama berasal dari keluarga (Nichols dan Schwartz, 2006).

McGrath dan Murray (dalam Weinberger \& Harrison, 2011) menyatakan bahwa penelitian mutakhir di bidang skizofrenia menunjukkan bahwa trajectory gangguan ini dapat berasal dari faktor risiko pengalaman traumatis selama tumbuh kembang dalam 
keluarga. Bowen (dalam Nichols dan Schwartz, 2006) mengatakan bahwa dalam membangun relasi, setiap individu dipengaruhi oleh tingkat individualitas (individuality) dan kebersamaan (togetherness). Setiap orang membutuhkan pertemanan dan kemandirian dalam tingkat tertentu. Ada delapan konsep dalam teori relasi keluarga Bowen yaitu: differentiation of self, emotional triangles, nuclear family emotional system, family projection process, multi-generational transmission process, emotional cutoff, sibling position, dan societal emotional process. Namun harus diakui, tidak mudah bagi sebuah keluarga untuk membantu pemulihan ODS. Dibutuhkan keluarga yang mampu beradaptasi dengan perubahan yang terjadi. Hasil penelitian lain bahkan menunjukkan bahwa salah satu faktor pencetus kekambuhan adalah keluarga yang tidak mengerti tentang cara menangani perilaku ODS di rumah (Fadli \& Mitra, 2013). Baik disadari atau tidak, masing-masing anggota keluarga akan saling memengaruhi dengan kuat namun dengan cara yang tidak bisa diprediksi (Nichols, 2009).

Dengan demikian, sangat penting bagi seluruh anggota keluarga untuk dapat membangun relasi yang sehat agar keadaan ODS stabil, terutama ketika ODS masih tergolong remaja. Remaja memiliki tugas perkembangan yang meliputi kognitif, emosi, sosial, dan fisik (Hurlock, 1991). Secara umum, Piaget juga menggambatkan tahap perkembangan remaja sebagai tahap identity vs identity confussion. Tahap ini ditandai dengan pencarian jati diri; siapa mereka sebenarnya dan apa yang mereka akan lakukan di masa yang akan datang (Santrock, 2009). Jika remaja menemukan jati diri yang salah, hal ini tentu akan membawa pengaruh buruk di tahap perkembangan berikutnya. Selain itu perlu diingat bahwa prognosis skizofrenia untuk onset remaja cenderung lebih buruk dibandingkan onset setelah masa remaja (Pramudya, 2014). Melihat pentingnya peran keluarga pada ODS remaja, peneliti tertarik untuk melihat dinamika relasi dalam keluarga pada ODS. Berdasarkan latar belakang di atas, maka masalah penelitian ini adalah: Bagaimana gambaran dinamika relasi keluarga pada ODS remaja berdasarkan teori Bowen?

\section{Metode}

\section{Partisipan penelitian}

Penelitian menggunakan single case study melalui wawancara terhadap empat orang yang berasal dari satu keluarga (ayah, ibu, dan dua anak perempuan). Index Person adalah anak perempuan terkecil. Semua partisipan dalam penelitian ini diambil menggunakan teknik purposive sampling dan diperlakukan sebagai case on hand. Untuk itu, peneliti mencari keluarga partisipan yang diharapkan dapat menyediakan informasi sesuai kebutuhan dan dapat menjawab tujuan penelitian (Kumar, 2005). Keluarga partisipan diperoleh dari penyebaran informasi di komunitas rohani di mana peneliti bergabung. Mereka diminta untuk memberikan izin (consent) sebelum wawancara dimulai. 
Karakteristik partisipan penelitian adalah sebagai berikut: (1) Sebuah keluarga inti (orang tua dan anak) yang salah satu anggotanya mengalami skizofrenia (ODS) dan onset terjadi saat partisipan berusia remaja. Batasan masa remaja menurut Erikson (dalam Santrock, 2006) adalah 12-20 tahun. (2) ODS remaja tersebut telah mendapat penetapan diagnosis skizofrenia dari psikiater dan telah mengonsumsi obat anti psikotik. Secara spesifik, jenis skizofrenia yang diambil adalah paranoid. Tipe ini merupakan skizofrenia dengan angka kejadian tertinggi (Sumekar dan Zahnia, 2016).

\section{Pengumpulan data}

Wawancara adalah percakapan dan tanya jawab yang diarahkan untuk mencapai tujuan tertentu (Poerwandari, 2017). Wawancara dilakukan dengan panduan umum dengan mencantumkan isu yang perlu diliput tanpa menentukan urutan pertanyaan. Tujuannya adalah untuk menemukan permasalahan secara lebih terbuka, dimana pihak yang diajak wawancara dimintai pendapat dan ide-idenya (Sugiyono, 2007).

Dalam penelitian ini, pendekatan yang dilakukan adalah secara kualitatif karena bertujuan mendapatkan gambaran secara menyeluruh sesuai yang terjadi di lapangan (Creswell, 2012). Data diperoleh melalui wawancara yang dirancang untuk menangkap delapan konsep utama dari Bowen sebagai berikut: differentation of self, emotional triangles, nuclear family emotional process, family projection process, multi-generational transmission process, emotional cutoff, societal emotional process dan sibling position. Wawancara dilakukan sekitar 2-3 kali per partisipan dan dilakukan sendiri oleh peneliti. Satu kali wawancara berdurasi 60-90 menit, tergantung dari tingkat kesiapan partisipan untuk menjawab. Jika partisipan terlihat tidak ingin melanjutkan, maka wawancara akan dihentikan dan dilanjutkan pada kesempatan berikutnya sesuai dengan kesepakatan yang dibuat peneliti dan partisipan

\section{Analisis data}

Analisis data penelitian mengacu pada delapan konsep utama dari Bowen yang sudah dipakai sebagai panduan wawancara. Koding dan analisis dilakukan berdasarkan konsep triangulasi emosi. Triangulasi emosi di sini berarti bahwa jawaban masing-masing partisipan akan dikonfirmasi atau dikontestasi oleh partisipan lain di dalam keluarga tersebut baik secara linier maupun sirkular. Analisis linear dilakukan untuk memahami hubungan sebab akibat langsung dari tema-tema hubungan emosional antar partisipan. Analisis sirkular berusaha memahami hubungan sebab akibat yang bersifat dimediasi oleh faktor-faktor tertentu seperti posisi atau peranan partisipan di dalam hubungan antara keluarga, pengalaman separasi atau kekerasan, dan sebagainya. Hasilnya akan menjadi gambaran dinamika relasi antar anggota keluarga yang berkembang bersama dalam unit interpersonal institusi keluarga. Triangulasi emosi ini penting dalam untuk menggambarkan dinamika hubungan dalam sistem keluarga yang tidak sekedar bersifat dyadic (menyangkut dua orang), tetapi lebih dari itu, bahkan dapat bersifat lintas generasi. 
Dinamika lintas generasi (vertikal) perlu dicari melalui wawancara untuk memahami faktor risiko yang telah ada di dalam relasi orang tua. Bowen (dalam Nichols dan Schwartz, 2006) juga percaya bahwa dalam setiap relasi, terdapat pihak ketiga yang dianggap sebagai penyeimbang. Pihak ketiga tersebut akan berperan baik jika kedua pihak yang lain kembali memiliki relasi yang sehat. Sebaliknya, pihak ketiga ini dianggap memperburuk relasi jika masing-masing pihak tidak membereskan masalah yang sebenarnya dan hanya berfokus pada pihak luar. Oleh karena itu, triangulasi emosi sistemik, baik vertikal maupun horisontal antar anggota keluarga harus dapat dipetakan dengan jelas agar data yang diperoleh mencerminkan data sistem dan individu sekaligus.

\section{Hasil}

Pada bagian hasil akan dipaparkan gambaran umum partisipan dan triangulasi emosi anggota keluarga yang mempengaruhi dinamika relasi sehingga menyebabkan IP mengalami gangguan kejiwaan. Seluruh paparan dalam bagian hasil ini juga dianalisis menggunakan kacamata vertikal-horisontal dan linear-sirkular. Pada bagian pertama, penulis memberi contoh bagaimana kacamata tersebut digunakan di dalam analisis relasi antar anggota keluarga. Seluruh nama yang tercantum merupakan nama samaran.

Tabel 1.

Gambaran Umum Partisipan Penelitian

\begin{tabular}{lllll}
\hline Data Demografis & Partisipan 1 & Partisipan 2 & Partisipan 3 & Partisipan 4 (IP) \\
\hline Nama Samaran & Elang & Magnolia & Peony & Rose \\
Usia & 54 tahun & 41 tahun & 22 tahun & 17 tahun \\
$\begin{array}{l}\text { Pekerjaan } \\
\text { Agama }\end{array}$ & Sopir Taksi & Ibu Rumah Tangga & Karyawan & Tidak Bekerja \\
$\begin{array}{l}\text { Suku Bangsa } \\
\text { Pendidikan }\end{array}$ & Kristen & Kristen & Kristen & Kristen \\
$\begin{array}{l}\text { Terakhir } \\
\text { Anak Ke, dari }\end{array}$ & SMA & Jawa & Ambon-Jawa & Ambon-Jawa \\
Status Pernikahan & SMP & SMK & SD \\
\hline
\end{tabular}




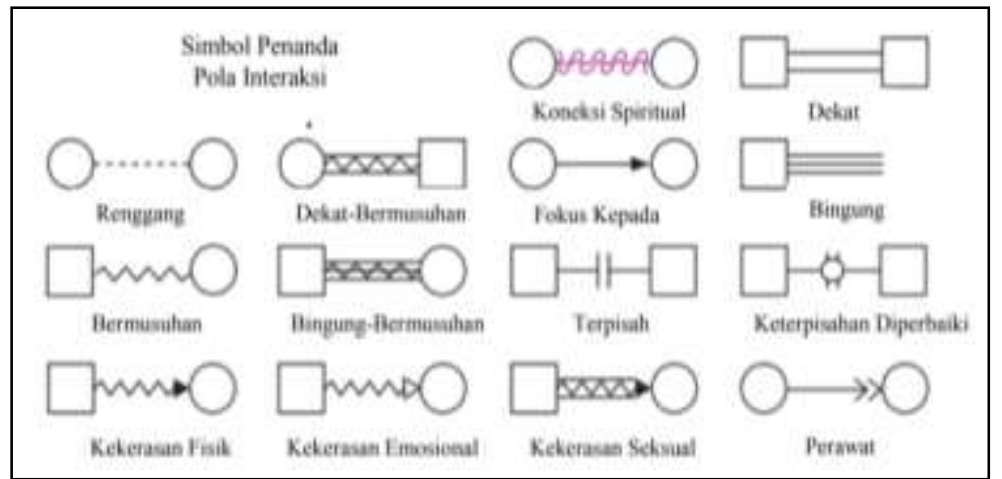

Gambar 1. Gambar simbol penanda interaksi

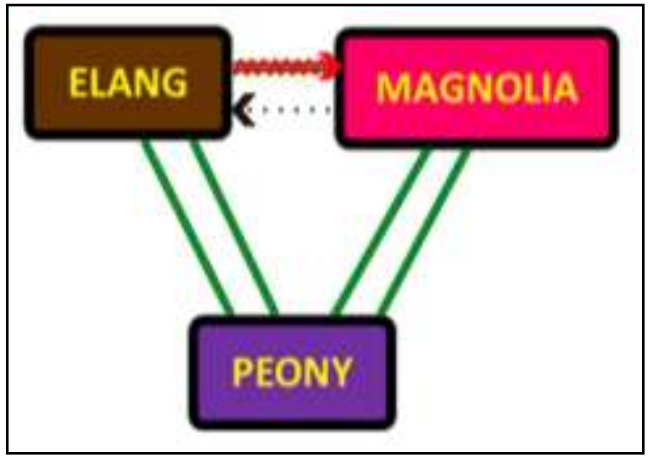

Gambar 2. Gambar triangulasi pertama

Jika dianalisis secara horizontal linear, dapat dikatakan bahwa Elang memiliki relasi yang cukup lekat dengan Magnolia, hal ini berarti di satu sisi Elang merasa dekat dengan Magnolia, namun ia juga melakukan kekerasan baik emosional dan fisik terhadap Magnolia, sebaliknya Magnolia menjadi pribadi yang relatif pasrah terhadap perlakuan Elang. Baik Elang maupun Magnolia bersikap biasa saja (tidak ada tuntutan secara khusus ataupun harapan tertentu) terhadap Peony. Peony juga hanya bisa bersikap pasrah, tidak ada keinginan untuk membantah dan menerima saja perlakuan kedua orang tuanya. Triangulasi ini ada sebelum Rose (IP) menjadi bagian dari keluarga. Lebih lanjut, analisis vertikal-sirkular dari triangulasi emosi ini tampak tidak sehat. Elang adalah individu yang tidak dapat memisahkan diri dari kelekatan emosi dengan keluarga asalnya (diferensiasi buruk dengan keluarga asal). Hal ini yang kemudian menyebabkan Ia menjadi pribadi yang mudah terpancing emosi dan juga reaktif jika terjadi sesuatu pada keluarga intinya. 
Serupa dengan Elang, Magnolia juga tidak bisa memisahkan diri dari kelekatan emosi dengan keluarga asalnya (diferensiasinya buruk). Hal ini menyebabkan Ia juga mengalami kesulitan untuk bisa menyesuaikan diri dengan cara Elang berinteraksi. Magnolia menjadi pribadi yang mudah menangis dan reaktif. Di sisi lain, Peony hanya dapat menerima semua itu sebagai situasi yang tidak dapat dihindari dan dilawan. Posisi Peony sebagai anak putri satu-satunya dapat dikatakan aman karena ia tidak menjadi objek proyeksi dari kedua orang tuanya. Peony mampu menunjukkan sikap sebagai anak yang baik sehingga Elang dan Magnolia tidak memiliki kecemasan bahwa ia akan tumbuh menjadi anak nakal yang tidak bisa memenuhi harapan orang tua. Dengan sifat Peony yang relatif baik, Elang dan Magnolia seharusnya berfokus untuk bisa membangun relasi mereka sebagai suami dan istri, namun ternyata hal ini tidak terjadi. Elang tetap menjadi pribadi yang reaktif bahkan menjadikan Magnolia sebagai objek pelampiasan kemarahannya. Sementara itu, Magnolia yang awalnya reaktif akhirnya selalu berusaha tegar dengan menggunakan rasionalitas dan mematikan emosi atas apa yang dialami. Ia juga melakukan emotional cutoff dari keluarga asalnya karena tidak ingin dipersalahkan atas pilihannya menikah dengan Elang.

"gak pernah cerita. Bapak di kampung, kalo ibu udah meninggal, jadi gak pernah cerita. Mereka gak pernah tau. Tante juga gak mau cerita, nanti takut disalahin, kenapa dulu mau nikah. Jadi tante gak mau cerita" (Magnolia)

"Ke masnya, tante juga gak mau cerita. Buat apa cerita, dia juga gak berani apa-apa. Om kan orangnya begitu. Jadi masnya tante juga gak akan berani" (Magnolia)

Reaksi Magnolia yang menurut saja, ternyata tidak berhasil mengubah sikap dan kualitas relasinya dengan Elang. Ia tetap merasa cemas ketika berhadapan dengan suaminya, terutama ketika ada masalah keluarga. Kecemasan ini kemudian berdampak pada Peony. Awalnya, penularan kecemasan relasi dari Elang dan Magnolia belum tampak kuat karena Peony masih kecil. Namun seiring berjalannya waktu, Peony semakin dewasa dan Rose sudah lahir juga, kelak multi-generational transmission akan tergambar semakin jelas. Pada triangulasi pertama ini, akar masalahnya adalah relasi yang buruk antara Elang dan Magnolia sebagai suami dan istri. Lalu relasi buruk yang tidak pernah dibereskan ini kelak akan terbawa/ditularkan pada kedua anaknya, baik Peony dan juga Rose (IP). 


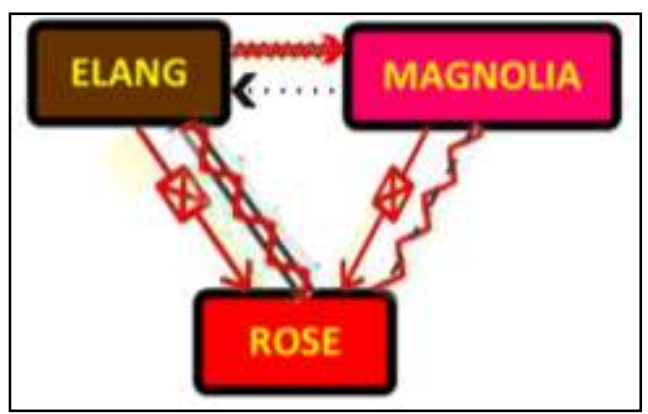

Gambar 3. Gambaran triangulasi kedua

Secara umum, relasi emosi pada triangulasi ini lebih intens daripada triangulasi pertama. Hal ini artinya Elang menjadi individu semakin dominan bahkan kerap melakukan kekerasan baik secara verbal maupun fisik terhadap Magnolia dan kini juga terhadap Rose (IP). Di sisi lain, Magnolia tetap saja menjadi pribadi yang relatif pasrah, namun ia juga mulai menjadi ibu yang banyak menuntut terhadap Rose (IP). Pada titik ini, baik Elang atau Magnolia sebagai orang tua mulai merasa bahwa Rose (IP) tidak akan bisa menjadi anak yang baik seperti kakaknya, Peony. Elang dan Magnolia cemas dan merasa bahwa Rose (IP) adalah seorang anak yang nakal, sulit diatur dan tidak akan bisa memenuhi harapan mereka untuk menjadi anak yang baik seperti halnya Peony.

"Rose ngomongnya juga telat. Umur 3-4 tahun belom bisa ngomong jelas. Ngomong Rose bilangnya oe. Kalo Peony dari kecil udah pinter. Jalan cepet, ngomong cepet. 14 bulan udah jalan, gak lama ngomong" (Magnolia)

"Tante suka bilang kalo disuruh diem ya diem, tapi dia gak dengerin. Makin kenceng teriak. Rose gak ngerti kalo dikasih tau. Beda sama Peony, kalo dikasi tau ngerti" (Magnolia)

"Peony dewasa, bisa diajak curhat, ngobrol, jadi penghiburan. Kalo Rose bisanya bikin kesel" (Magnolia)

Kecemasan mereka terhadap sifat Rose (IP) telah membuat pasangan suami istri ini berfokus untuk seakan-akan membenahi sikap Rose (IP) yang buruk dengan harapan bisa mengubahnya menjadi anak yang baik, alih-alih membenahi relasi mereka sebagai suami istri yang sudah rusak semenjak lama. Dalam usahanya mengubah Rose (IP) menjadi anak yang baik, Elang bahkan tidak akan ragu untuk menggunakan tindak kekerasan. 
"Rose cerita, kesel sama papanya.Trus sama papanya dia diambilin balok. Tante langsung jangan pa, jangan. Baloknya gede banget. Sering begitu. Om gak cuma ngancem, kalo udah ngomong pasti dikerjain" (Magnolia)

Elang dan Magnolia yang sebenarnya tidak mampu melakukan diferensiasi dengan baik dari keluarga asal, malah merasa dan memproyeksikan bahwa Roselah (IP) yang nakal dan gagal untuk bisa menjadi anak yang baik. Mereka bahkan menganggap Rose sebagai sumber masalah keluarga. Dengan anggapan bahwa Rose adalah sumber masalah dalam keluarga, mereka berdua terus melakukan berbagai upaya yang dianggap baik dan tepat untuk bisa mengoreksi perilaku Rose dan membuatnya menjadi anak yang lebih baik. Elang dan Magnolia sebagai generasi kedua justru menularkan kecemasan mereka pada generasi ketiga. Rose kemudian bertumbuh dengan emosi yang labil karena selalu dinilai tidak baik dan diperlakukan seperti barang rusak yang harus selalu diperbaiki setiap waktu agar tidak membuat kondisi keluarga semakin memburuk. Dengan adanya penularan kecemasan dari Elang dan Magnolia, akhirnya Rose (IP) mengalami kecemasan mengenai identitas dirinya. Hal ini yang kemudian menyebabkannya menjadi individu dengan emosi yang labil.

"kalo sedih aku berdoa, langsung sakit hati, emang aku kayak nenek sambil nangis mukul kaca. Kesel." (Rose)

"rasanya pengen bunuh diri tapi engga bisa. Main ujan ampe jam 12 malam biar masuk angin. Engga masuk angin." (Rose)

"abis dibully. Trus aku tiba-tiba nangis kayak ngamuk sedih gitu. Tiba-tiba ngaca trus aku pengen mukul kaca." (Rose)

Dengan kondisi lingkungan yang kerap menyalahkannya, Rose (IP) lalu melakukan emotional cutoff. Ia ingin menghindar dari Elang dan Magnolia yang selalu menganggap dirinya bermasalah dan perlu diperbaiki. Hal ini membuatnya tidak mau lagi bercerita dan memilih untuk memendam apa yang dirasakan. Rose (IP) merasa dirinya tidak disayang.

"mama, aku tadi di sekolah dikatain gini gini, trus mama bilang yauda, sini makan" atau gak mama bilang "iyalah, kamu tingkahnya begini begini, salah sendiri"(Rose)

"Aku simpen di hati sampe akhirnya masuk rumah sakit"(Rose)

"Trus aku dicuekin mama ama papa, kayak enggak sayang gitu"(Rose)

Walaupun Elang dan Magnolia terus berusaha memperbaiki sikap Rose bahkan dengan tindak kekerasan, namun Rose (IP) tidak pernah berani membalas Elang. Rose 
memilih untuk melampiaskan kekesalannya kepada Magnolia. Tindakan Rose (IP) yang hanya melampiaskan marahnya pada Magnolia bukanlah tanpa sebab. Alasan dibalik tindakan Rose memukul Magnolia akan dijelaskan pada triangulasi emosi yang lain.

Pola emosi labil dalam keluarga, disebut Bowen sebagai nuclear family emotional process. Menurutnya, pasangan suami istri yang tidak mampu menyelesaikan proses diferensiasi mereka dengan baik, di kemudian hari akan memunculkan dampak negatif, salah satunya adalah konflik dalam pernikahan.

"tante diajak hubungan, sekitar jam 2 malem. Tante gak mau karena cape. Tau tau tante ditarik, trus dilempar ke tembok dua kali. Abis itu tante mental keluar pintu, diambil, mau dilempar lagi, terus tante bilang Tuhan Yesus tolong, abis itu tante gak jadi dilempar, ditaro di kasur. Tante ditelentangin. Kaki tante di bawah, mau ditonjok lagi. Tante ngomong, tolong pa, aku belum mau mati, tolong pa, tolong jangan, sambil nangis. Dia kaget lihat kepala tante udah berdarah, dia bilang Tuhan Yesus! Kepala tante isinya pasir karena kan rumahnya belom jadi. Abis itu tante dilap, digantiin baju, dipakein helm, langsung dibawa naik motor ke rumah mamanya. Tangan tante gak bisa digerakin. Trus ada satpam yang nyamperin mungkin karena denger tante teriak. Terus satpam bilang, kalo ada apa-apa bilang pak, terus satpamnya disogok dikasi uang, jadi diem aja. Padahal kepala tante masih berdarah, tante dibawa ngebut malem malem. Tangan tante cuma sebelah yang pegangan. Kalo gak tante bisa jatoh"

Selain konflik dalam pernikahan, dampak negatif kedua dari ketidakmampuan melakukan diferensiasi adalah menjadi pasif lalu tidak mampu menjalankan peran dengan baik. Dalam hal ini, Magnolia pasrah dan menerima saja segala yang terjadi. Ia tidak mampu menjalankan perannya sebagai ibu dengan baik karena pada dasarnya ia adalah pribadi yang dipenuhi kecemasan dan melakukan emotional cutoff dalam mengasuh anak-anaknya.

"Trus aku dicuekin mama ama papa, kayak enggak sayang gitu"(Rose)

" aku cerita, tapi mereka gak ke sekolah belain aku, cuma dengerin doank" (Rose)

Dampak yang terakhir dari diferensiasi yang buruk adalah adanya gangguan emosional/psikologis pada salah satu anak di dalam keluarga. Hal ini terjadi pada Rose (IP). Dapat dikatakan, bahwa Rose telah menjadi korban dari kekurang-mampuan Elang dan Magnolia di dalam melakukan diferensiasi dari keluarga asal. 


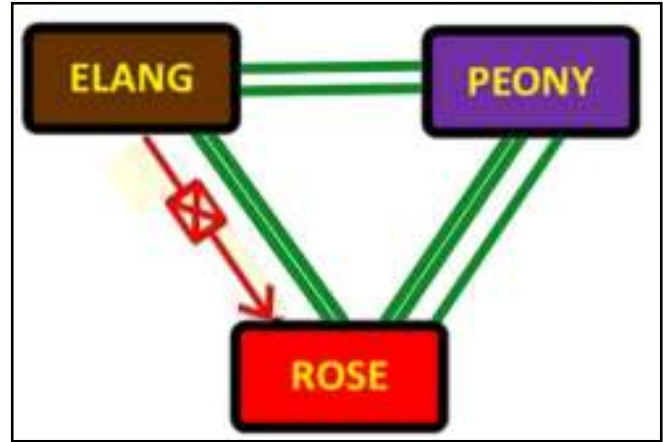

Gambar 4. Gambaran triangulasi ketiga

Secara umum, tekanan emosi pada triangulasi ini lebih dalam. Memang Elang memiliki tuntutan tinggi terhadap Rose untuk bisa menjadi anak baik, namun hal ini tidak ditambah dengan tuntutan tinggi dari Magnolia seperti pada triangulasi sebelumnya. Pada triangulasi ini, peran Magnolia digantikan oleh kakaknya yaitu Peony. Sebagai anak sulung, memang sudah sewajarnya jika Peony memiliki tuntutan terhadap Rose (IP) untuk menghormati dan menghargainya. Namun demikian, tuntutan dari Peony tidak sedalam tuntutan dari Magnolia. Hal ini juga terjadi karena Peony sendiri tidak mendapat tekanan emosi yang tinggi dari Elang seperti halnya Magnolia. Dengan demikian, Peony tidak perlu melampiaskan emosinya kepada Rose (IP). Peony tidak mendapatkan tuntutan tinggi dari Elang karena ia sudah dianggap sebagai anak yang baik dan berhasil.

"Sayang juga sama Peony, cuma kan saya mikirnya dia udah kerja, udah bisa beli barang sendiri. Tapi kalo Senin pagi, saya selalu kok nawarin Peony mau dianterin apa gak sampe kantor di Jakarta. Tapi Peony yang gak mau, katanya kasian sayanya ntar kecapean. (Elang)

Dalam teori Bowen, tuntutan Peony kepada Rose (IP) dipengaruhi oleh urutan dalam kelahiran (sibling position). Seperti telah disinggung di atas, sebagai anak sulung Peony akan bersikap lebih dominan kepada Rose, ditambah lagi jarak usianya lima tahun. Tanpa disadari ada perasaan bahwa kasih sayang dari Elang dan Magnolia akhirnya direbut oleh kehadiran Rose (IP). Namun demikian, hal ini tidak terlalu menganggu relasi emosi antara Rose dengan Peony. Hal ini terjadi karena Peony telah melakukan diferensiasi dengan cukup baik.

Dengan berkurangnya intensi emosi dari Peony, Rose mampu bersikap lebih baik terhadap tuntutan emosi dari Elang. Dengan respon Rose yang lebih baik kepada Elang, Elang juga mampu menunjukkan sikap yang lebih baik kepada Rose (IP). Dalam 
triangulasi ini, sikap Elang terhadap Rose lebih lunak, hal ini menyebabkan Rose (IP) berani mendekat dan terikat secara emosi pada Elang.

"aku deketnya sama papa. Kalo sama mama gak terlalu deket. Kalo mama itu lebih deket sama kakak. Mungkin karena kakak anak pertama kali ya. Udah keliatan aja, dari kecil juga begitu, kakak seringnya sama mama, aku lebih seringnya sama papa. Papa juga pernah bilang, kalo aku deketnya sama papa, kalo kakak sama mama" (Rose)

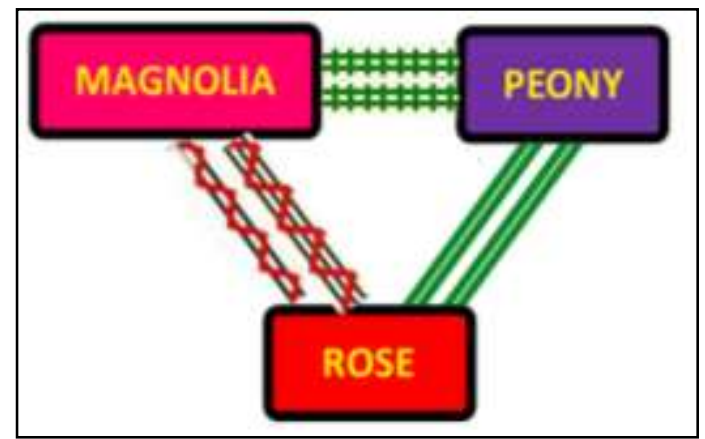

Gambar 5. Gambaran triangulasi keempat

Secara umum, dapat dikatakan bahwa relasi emosi pada triangulasi ini tidak baik. Magnolia dalam perannya sebagai ibu bagi kedua anaknya tidak berhasil meregulasi emosinya dengan baik. Magnolia yang telah melakukan diferensiasi lantas dipenuhi dengan kecemasan dalam membesarkan anak-anaknya. Cara Magnolia dalam mengasuh kedua anaknya sangat berbeda. Terhadap Peony yang ia baik dan bisa memenuhi harapan, Magnolia tidak memiliki tuntutan emosi yang tinggi. Ia bersikap ramah dan merasa senang terhadap keberadaan Peony.

"Peony dewasa, bisa diajak curhat, diajak ngobrol, jadi penghiburan" (Magnolia)

"Misalnya nih Peony boleh ke tempat tidur tante, kalo Rose gak boleh. Soalnya Rose jorok juga."(Magnolia)

Sebaliknya, berbeda dengan Magnolia, ia justru memiliki tuntutan emosi tinggi kepada Rose (IP) yang dianggap tidak bisa menunjukkan sikap baik dan gagal memenuhi tuntutannya sebagai orang tua. Dengan persepi Magnolia, bahwa Rose adalah anak bermasalah dan perlu berubah, ia malah berfokus untuk terus memperbaiki sifat Rose (IP) agar bisa menjadi anak baik dan mampu memenuhi harapan keluarga. Dengan perbedaan sikap yang ditunjukkan, Rose (IP) kemudian merasa bahwa dirinya tidak disayang oleh Magnolia.

"Rose suka nanya tante. Ma, sebenernya mama sayang gak sih sama Rose"(Magnolia) 
Perasaan tidak disayang ini menyebakan Rose (IP) melakukan emotional cutoff dari Magnolia. Rose (IP) lebih memilih untuk mempersepsikan bahwa dirinya lebih memiliki ikatan emosi kepada Peony dan Elang, bukan Magnolia.

"Aku lebih deket sama papa dan kakak. Kalo sama mama gak terlalu deket"(Rose)

Perbedaan sikap dari Magnolia kepada Rose (IP) dan Peony kemudian tanpa disadari telah membuat Rose tidak menyukai keberadaan Magnolia. Hal inilah yang menyebabkan jika sedang marah dan emosinya tinggi, Rose kerap kali memukul dan bersikap kasar terhadap Magnolia. Magnolia dijadikan pelampiasan oleh Rose.

"ga lega, pengennya mau nangis terus, mukul mama, tapi kalo mukul mama nanti dosa. kesel banget, ga tahan. Pengen pukul mama bawaannya, kesel mau pukul dia, teman yang ngatain aku udah pulang, yang ada cuma mama jadi mukul mama aja" (Rose)

Rose (IP) juga melakukan tindakan kekerasan kepada Magnolia karena ia melihat pola yang sama dari Elang. Rose yang di satu sisi merasa terikat emosi pada Elang, akhirnya melakukan modeling dari tindakan Elang terhadap Magnolia.

"aku kayak papa, galaknya, suka emosian. Suka teriak. Cara mukulnya kayak papa, keras, sampe benjol orang. (Rose)

Sementara itu, relasi emosi antara Peony dan Rose terlihat cukup baik. Rose (IP) tidak menunjukkan sikap bermusuhan atau iri hati. Hal ini terjadi karena sikap Peony yang tetap ramah dan hangat terhadap Rose (IP). Hal ini membuat Rose (IP) merasa semakin marah kepada Magnolia yang dianggap sebagai satu-satunya anggota keluarga yang tidak mampu bersikap baik terhadap dirinya. Dalam triangulasi ini, dapat dikatakan bahwa akar masalahnya terletak pada persepsi Magnolia yang salah dan secara konsisten menganggap Rose (IP) adalah anak bermasalah dan menjadikannya objek proyeksi. Sikap ini disebut sebagai multi-generational transmission process. 


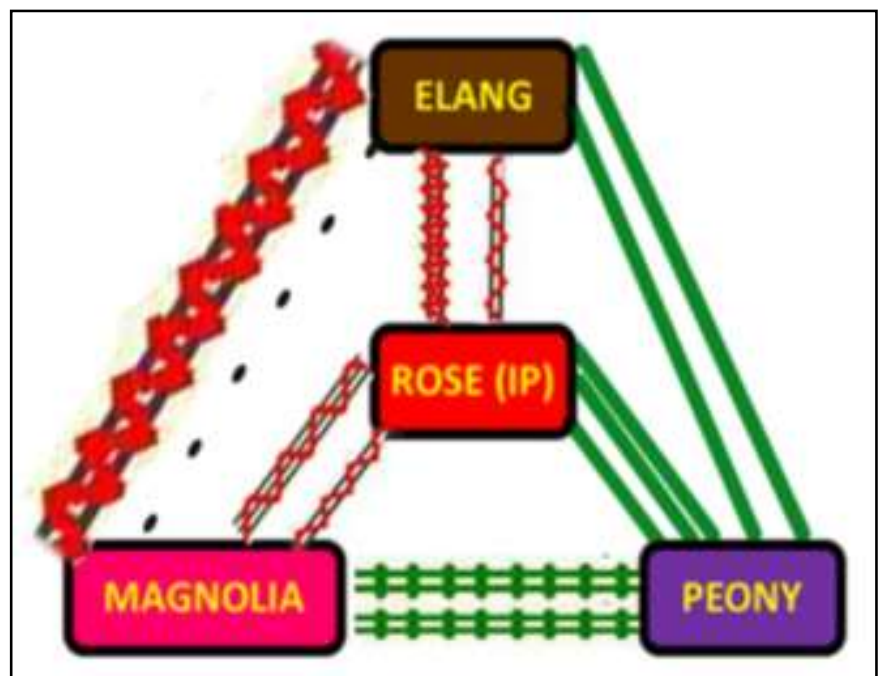

Gambar 6. Gambaran relasi seluruh anggota keluarga

Dari visualisasi di atas, terlihat ada relasi emosi yang tinggi dari Elang dan Magnolia terhadap Rose (IP). Muncul kesan bahwa kedua orang tua ini menginginkan Rose (IP) bisa berubah menjadi anak yang lebih baik dan memenuhi harapan mereka. Tanpa disadari, tuntutan mereka terhadap Rose (IP) sebenarnya adalah proyeksi dari ketidakmampuan mereka melakukan diferensiasi dari keluarga asal. Pada keadaan ini, Rose (IP) menjadi korban karena dijadikan sebagai objek proyeksi (family projection process).

Kemudian, dalam usaha Elang dan Magnolia memperbaiki Rose, mereka malah memberikan pesan ganda atau yang disebut Bateson (dalam Gibney, 2006) sebagai double bind. Elang dan Magnolia yang tidak mampu meregulasi dirinya malah secara konsisten memberi tindakan/perlakuan yang berbeda dari ucapan yang keluar dari mulut mereka. Hal ini menimbulkan kebingungan dalam diri Rose (IP) yang kemudian menjadi faktor pemicu munculnya gangguan psikologis pada Rose.

Pesan ganda dari Elang kepada Rose :

"Papa itu, kalo Rose lagi gak bertingkah ya baik banget. Dipeluk, diselimutin. Beliin makanan aja buat Rose doank. Tapi ya kalo lagi marah, kata-katanya kasar lagi. Sekarang juga begitu, tapi ya kata-katanya udah berkurang jauh." (Peony)

Pesan ganda dari Magnolia kepada Rose :

"mama bilang sayang, tapi kalo lagi marah, kata-kata mama ke dia kasar. Cuma sekarang udah berkurang. Bisa keluar tuh kata-kata bego, gila. Itu dari sebelum dia sakit. (Peony)

Dengan input emosi yang memberi pesan berbeda dari anggota keluarga lain, Rose (IP) memberikan respons yang berbeda pula pada masing-masing pihak. Terhadap Elang dan Peony, Rose (IP) bersikap relatif normal dan baik. Namun Rose (IP) menunjukkan ketidaksukaannya kepada Magnolia. Hal ini terjadi karena Rose merasa tidak disayang 
oleh Magnolia. Rose percaya bahwa Magnolia lebih sayang Peony dibandingkan dirinya. Hal ini yang menyebabkan hingga jika Rose kesal, ia menjadikan Magnolia sebagai pelampiasannya.

Dari sisi Peony, dapat dikatakan bahwa ia cukup mampu meregulasi emosinya sehingga sikapnya terhadap Elang, Magnolia dan Rose (IP) relatif lebih netral. Beberapa faktor yang menyebabkan differentiation of self pada Peony lebih baik adalah karena ia memiliki kemampun intelijensi yang baik sehingga mampu menggunakan akal sehat dalam bertindak dan membuat keputusan.

Bagian terakhir adalah Elang. Sikap Elang kepada Magnolia didasari oleh kecemasan karena belum berhasil melakukan diferensiasi. Jauh sebelum ada Rose, Elang telah menjadikan Magnolia sebagai objek proyeksinya. Elang seringkali merasa tidak aman dan mencurigai Magnolia yang dianggap memiliki hubungan dekat dengan pria lain.

"Jadi gini, misalnya mama beli aqua banyak, terus ditukerin di tukang loak, dapet gelas, nah gelasnya dibanting. cemburu. Pokoknya gak boleh ada barang dari luar, apalagi cowo walopun tukang loak. Jadi dianggepnya mama ngobrol sm tukang loak. Keluar gak boleh. Bergaul sama tetangga gak boleh. Kalo ke pasar ditemenin papa. Belanja tukang sayur gak boleh lama-lama, harus pake baju ketutup"(Peony)

Kecurigaan yang terus menerus dari Elang terhadap Magnolia ini menjadi dasar pola emosi dalam keluarga. Dengan demikian, relasi dalam keluarga menjadi tidak baik dan malah menimbulkan konflik di dalam pernikahan. Dengan sikap Elang yang selalu mendominasi, Magnolia akhirnya menjadi sosok yang pasrah, menutup diri dan kemudian tidak berfungsi dalam rumah tangga. Dengan kondisi emosi Elang dan Magnolia yang buruk, relasi dalam keluarga menjadi tidak sehat lalu memicu anak yang paling vulnerable menjadi objek proyeksi. Rose (IP) menjadi korban dan pada akhirnya mengalami gangguan emosi bahkan gangguan kejiwaan.

\section{Diskusi}

Studi mengenai etiologi dan prognosis Skizofrenia modern cenderung memperkecil faktor risiko yang berasal dari lingkungan. Meskipun demikian, pandangan modern juga tidak dapat mengingkari adanya faktor-faktor risiko yang terkait dengan tumbuh kembang manusia, terutama dalam sistem proksimalnya - yaitu keluarga (McGrath \& Murray, dalam Weinberger \& Harrison, 2011); Krabbendam \& van Os, 2005). Teori Bowen menduduki posisi istimewa dalam berbagai bentuk sistem seperti keluarga, organisasi, kongregasi kepercayaan, organisasi korporasi dll karena teori ini banyak digunakan untuk melatih relawan dan pekerja di berbagai lembaga tersebut demi memahami dinamika emosionalitas dalam sistem (Rabstenjnek, 2015; Bregman \& White, 2010).

Dalam kajian pustaka, peneliti mengalami kesulitan serius untuk memperoleh kajiankajian serupa, terutama di Indonesia. Skizofrenia merupakan topik yang cukup populer, 
tetapi penelitian lebih banyak dilakukan dengan metode survei (Fadli \& Mitra, 2013; Fatmawati, 2016; Suryani, et al. 2014) atau uji klinis metode terapi tertentu dengan rancangan pra-pasca paparan terhadap intervensi (Yusuf, S., 2013; Asmoro \& Widi, 2016; Pardede, 2017; Arief, 2019). Penelitian yang mengacu pada perjalanan hidup klien dan menelisik dinamika relasi antar keluarga secara detil dan multidimensi (vertikal horisontal, liner dan sirkular) seperti dalam penelitian ini belum penulis temukan pada kajian pustaka di Indonesia. Hal itulah yang membuat penelitian ini unik sekaligus konsisten dengan tujuan psikologi klinis yang sangat menghargai keunikan setiap manusia. Model Terapi Keluarga Bowen jelas memberikan peluang pada setiap individu yang terjalin dalam hubungan emosional dengan IP (klien) untuk menunjukkan kontribusinya dalam sistem keluarga yang memicu episode sehingga psikoterapis dapat merancang intervensi terapeutiknya sesuai dengan kebutuhan individu tersebut. Meskipun studi ini mempunyai keterbatasan serius karena merupakan suatu single-case study, tetapi model terapi Bowen memberikan perspektif yang utuh mengenai pihakpihak yang terkait dalam proximal system keluarga (closely-knit family system), dalam menjelaskan etiologi dan sekaligus prognosis bagi anggota keluarga yang mengalami skizofrenia. Teori Bowen sangat relevan dengan konteks sosial budaya di Indonesia karena mengakui adanya keterlibatan relasi lintas (trans) generasi yang dalam berbagai keragaman budaya kita merupakan kenyataan sosiologis hampir di setiap keluarga. Meskipun dalam keluarga modern mereka mungkin hidup terpisah-pisah atau dalam keluarganya sendiri, tetapi intensitas relasi lintas generasi masih cukup intens bagi banyak keluarga di Indonesia.

\section{Kesimpulan}

Berdasarkan masalah yang ingin diteliti, skizofrenia merupakan gangguan perilaku yang tidak hanya merupakan persoalan kemampuan melakukan diferensiasi self setiap anggota keluarga, tetapi juga difereniasi self yang merespons pada dinamik keluaga sebagai sistem. Kemampuan diferensiasi ini sangat dipengaruhi oleh intensitas relasi emosi dari anggota keluarga lainnya. Kemampuan diferensiasi diri yang berbeda ini pada akhirnya dapat memberikan gambaran dinamika relasi di dalam keluarga sesuai dengan tujuan penelitian. Dalam penelitian kali ini, objek proyeksinya adalah Rose (IP) yang dianggap sebagai anak yang tidak baik dan tidak bisa memenuhi harapan orang tua. Setelah proyeksi, hal berikutnya yang akan terjadi adalah multi-generational transmission process. Elang dan Magnolia yang sama-sama gagal melakukan diferensiasi dari keluarga asal, telah berhasil menularkan kecemasan kepada Peony dan Rose (IP), namun terlebih utama pada Rose. Selain itu dapat dilihat bahwa dalam usaha melakukan diferensiasi, semua anggota keluarga melakukan emotional cutoff. Elang dan Rose (IP) adalah individu yang paling reaktif dan paling emosional. Sebaliknya, Magnolia malah menjadi individu yang yang pasrah dan selalu berusaha merasionalisasikan segala hal. Kedua respons ekstrim 
ini tentunya tidak bisa mendukung hubungan relasional yang sehat dimana seharusnya emosi dan rasio sama-sama mempunyai peranan penting dalam berinteraksi.

Tiga dari empat partisipan biasanya akan mencari "pihak ketiga" jika sedang berada di dalam konflik. Pihak ketiga ini bisa berupa kegiatan seperti memancing, bermain telepon genggam, bercerita bahkan melakukan kegiatan rohani di gereja. Urutan kelahiran juga menjadi hal yang cukup penting. Peony yang lahir terlebih dahulu, lebih sedikit terpapar oleh kegagalan Elang dan Magnolia dalam melakukan diferensiasi. Sebaliknya, Rose (IP) justru lebih banyak terpapar oleh kegagalan Elang dan Magnolia. Dengan demikian, dapat ditarik kesimpulan bahwa terganggunya kejiwaan Rose (IP) dimulai dari diferensiasi yang tidak baik dari Elang dan Magnolia. Kemudian mereka menjadikan Rose sebagai objek proyeksinya dan terjadilah multi-generational transmission process. Hal ini membuat Rose membawa kecemasan dalam hidupnya. Selain itu, terjadi juga proses double bind yang membuat Rose semakin bingung akan lingkungan sosial terutama keluarga dan pada akhirnya membuatnya mengalami gangguan emosi bahkan kejiwaan.

\section{Saran}

Pada penelitian selanjutnya dengan topik serupa, dapat ditambah jumlah unit keluarga yang berpartisipasi. Dengan bertambahnya jumlah unit keluarga, diharapkan gambaran dinamika relasi keluarga yang diperoleh akan lebih kaya. Dapat juga dilakukan dengan variasi jumlah anak dan jenis kelamin. Dengan unit keluarga yang tidak homogen, diharapkan bahwa hasil yang diperoleh akan semakin kaya. Selain itu, dengan terus meningkatnya jumlah ODS di Indonesia, perlu dibuat lembaga yang memberikan layanan cara penanganan ODS secara terpadu. Lembaga ini diharap akan mampu mengedukasi unit keluarga untuk menciptakan kondisi rumah yang relatif kondusif dan didasari pada pembenahan sistem keluarga terlebih dahulu, termasuk juga di dalamnya edukasi kepada masyarakat sekitar tempat tinggal ODS. Selain itu, seiring berkembang pesatnya teknologi, perlu dibuat website dan mobile application dari lembaga yang bersangkutan. Diharapkan dengan kemudahan akses ini, pelayanan terhadap ODS akan semakin optimal. Lebih lanjut, diperlukan juga volunteer terlatih yang bisa stand by untuk memberi respons segera atas setiap pesan masuk baik melalui web atau aplikasi.

Hal lain yang perlu diingat, masa remaja merupakan masa krusial dalam perkembangan individu. Sangat penting bagi sekolah untuk membuat sistem yang dapat memberi rasa aman kepada murid agar tidak menjadi korban bullying yang kemudian akan memicu munculnya berbagai gangguan. Begitu juga dengan lembaga keagamaan, harus secara konsisten mengedukasi anggotanya untuk menghargai dan menghormati sesama.

\section{Kepustakaan}


Arief, M. F. (2019). Penerapan konseling Adlerian untuk mengurangi perasaan inferior dan mengingatkan social interest pada pasien Skizofrenia. Psikologi Sosial, (4) 137142.

Asmoro \& Widi, W. (2016). Penerapan terapi okupasi (menggambar) pada pasien skizofrenia dengan masalah keperawatan halusinasi pendengaran di ruang gelatik rumah sakit jiwa menur, Surabaya. (Skripsi sarjana, tidak diterbitkan). Univesitas Airlangga.

Bregman, O. C. \& White, C. (2011). Bringing systems thinking to life: Expanding the horizons for bowen family systems theory. Routledge

Chandra, L. S (November, 2010). Berbagai tantangan dalam penanganan klinis skizofrenia. Diunduh dari https://mafiadoc.com/07181-berbagai-tantangan-dalamklinis-kalbe 59d68cf81723dd286f7621a2.html

Creswell, J. W. (2012). Educational research: Planning, conducting, and evaluating quantitative and qualitative research. Pearson

Davison, G. C., Neale, J. M., Kring, A. N. (2004). Abnormal psychology (Edisi kedelapan). John Wiley \& Sons Corporation

Fadli, S.M., Mitra, M. (2013). Pengetahuan dan ekspresi emosi keluarga serta frekuensi kekambuhan penderita Skizofrenia. Kesma. National Public Health Journal, 7(10) 466470. http://dx.doi.org/10.21109/kesmas.v7i10.6

Fatmawati, I. N. A. (2016). Faktor-faktor penyebab skizofrenia. Studi kasus di RS jiwa daerah Surakarta. (Skripsi sarjana, tidak diterbitkan). Universitas Muhammadiyah, Surakarta.

Gibney, P. (2006). The double bind theory: Still crazy-making after all these years. Psychotherapy in Australia, 12(3), 48-55.

Hurlock, E. B. (1991). Psikologi perkembangan: Suatu pendekatan sepanjang rentang kehidupan. Erlangga

Ivanti, A. (2001). Peran dukungan sosial keluarga dalam mengurangi frekuensi kekambuhan penderita skizofrenia. (Skripsi sarjana, tidak diterbitkan). Universitas Katolik Indonesia Atma Jaya.

Krabbendam, L. \& Os, V. J. (2005). Schizophrenia and urbanicity: A major environmental influence-conditional on genetic risk. Schizophrenia Bulletin, 31(4), 795-799. http://dx.doi.org/10.1093/schbul/sbi060

Kumar, R. (2005). Research methodology: A step-by-step guide for beginners. Sage Publication.

Nichols, M. P, \& Schwarts. R. C (2006). Family therapy: Concepts and methods (Edisi ketujuh). Pearson

Nichols, M. P. (2009). The essentials of family therapy (Edisi keempat)Pearson

Pardede, S. (2017). Penerapan terapi suportif dengan teknik bimbingan untuk mengurangi dorongan bunuh diri pada pasien skizofrenia. Terapeutik. Jurnal Bimbingan dan Konseling. 1(1) 89-96. https://doi.org/10.26539/teraputik.11140 
Penentuan Kapasitas untuk Pengobatan penderita Skizofrenia. (2015, 31 Agustus). Diunduh dari https://www.ui.ac.id/berita/penentuan-kapasitas-untuk-pengobatanpenderita-skizofrenia.html

Poerwandari, E. K. (2017). Pendekatan kualitatif untuk pendekatan perilaku manusia. Lembaga Pengembangan Saran Pengukuran dan Pendidikan Psikologi (LPSP3)

Pramudya. (2014). Skizofrenia and the other psychotic. ICON

Rabstejnek. (2015). A brief review of self psychology. Diunduh pada 9 November 2020 dari https://www.researchgate.net/publication/284898645_A_Brief_Review_of_Self_Psyc hology

Riskesdas. (2013). Hasil utama riskesdas riskesdas 2013. Riset Kesehatan Dasar Kementerian Kesehatan Republik Indonesia.

Riskesdas. (2018). Hasil utama riskesdas 2018. Riset Kesehatan Dasar Kementerian Kesehatan Republik Indonesia

Santrock, J. W. (2006). Life span development (Edisi kesepuluh). Mc Graw Hill

Santrock, J. W. (2009). Life span development (Edisi kedua belas). Mc Graw Hill

Sugiyono. (2007). Memahami penelitian kualitatif. Alfabeta.

Sumekar, D. W. \& Zahnia, S. (2016). Kajian epidemologi skizofrenia. Majority. 5(5), 160166

Surilena. (2005). Pendekatan holistik terhadap skizofrenia. Jiwa: Majalah Psikiatri, 38(3), 6984

Suryani, Komariah, M., \& Karlin, W. (2014). Persepsi keluarga terhadap skizofrenia. Diunduh dari: http://pustaka.unpad.ac.id/wp-content/uploads/2016/10/11-persepsi-keluargatentang-skizofrenia.pdf

Taufik, M. (2013, 15 September). Di Indonesia ada 18 ribu penderita gangguan jiwa berat dipasung. Diunduh dari https://www.merdeka.com/peristiwa/di-indonesia-ada-18ribu-penderita-gangguan-jiwa-berat-dipasung.html

Tomb, D. A. (2004). Buku saku psikiatri (Edisi keenam). EGC

Weinberger, D. R. \& Harrison, P. J. H. (2010). Schizophrenia (3rd Ed.). Blackwell Publishing

Yusuf, A. A. (2013). Terapi keluarga dengan pendekatan spiritual terhadap model keyakinan kesehatan keluarga dalam merawat pasien Skizofrenia. Jurnal Ners. 8(1) 165-173. https://doi.org/10.20473/jn.v8i1.3897 